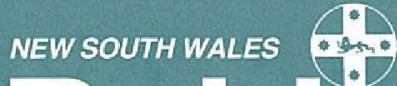 Public Health Bulletin
}

\section{HOSPITAL-RELATED MORTALITY IN NSW: PRELIMINARY RESULTS}

David Lyle, Shing Chung Fung, Paul Corben and Tim Churches, Epidemiology and Health Services Evaluation Branch, NSW Health Department.

\section{INTRODUCTION}

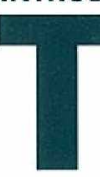

he use of hospital mortality rates as indicators of the quality of hospital care has been considered for some time. Since the release of hospital mortality indicators by the US Health Care Financing Administration in 1984 and $1986^{1}$, methods to improve their validity and reliability have developed, particularly in North America.

This article reports on a preliminary analysis of in-hospital mortality data and identifies the data needed to produce more valid and reliable versions of these indicators.

The mortality outcomes of hospitals or clinical services are influenced by many factors other than the quality of medical care. These include the patients' age, sex, clinical condition, illness severity, co-morbidity, treatment received before hospitalisation, hospital admission and discharge policies, and the type or role of the hospital. Adjustment for such factors is necessary before meaningful comparisons of mortality rates can be made among hospitals or across time for a given hospital. Information on many of these factors is not available from routine data systems.

As a first step in developing indicators of hospital-related mortality we examined deaths occurring in NSW hospitals over the past five years, focusing on the numbers and rates of in-hospital deaths, case-fatality rates (CFRs) for selected conditions, and variations in all-causes mortality within different categories of hospital. Only crude rates are presented here - there has been no attempt to adjust for even basic influences such as casemix, age and sex. The results of basic risk-adjusted analyses using available data will be reported in the near future. Our intention is to determine whether existing data will allow for the development of appropriate indicators or whether additional information is required.

\section{METHODS}

We analysed data on separations from all public and private hospitals in NSW over the five consecutive financial years between 1988-89 and 1992-93. The data source was the NSW Inpatient Statistics Collection. Analyses were based on the principal diagnosis or procedure, which was coded according to the International Classification of Diseases and Causes of Death, 9th Revision, Clinical Modification ${ }^{2}$ (ICD-9 CM). The following conditions or procedures were selected for review:

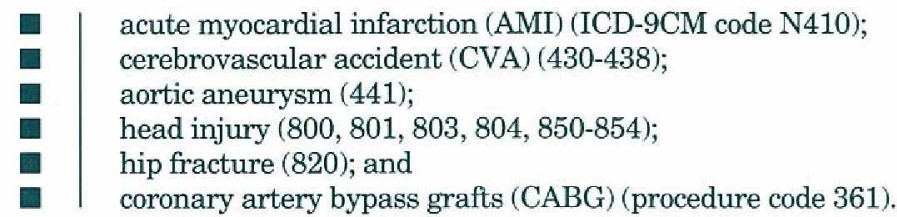

Hospitals were grouped according to a NSW Health Department classification which took into account the level of services provided, casemix complexity and hospital size ${ }^{3}$. Mortality trends were presented for seven public hospital groups:

\section{Contents}

\section{Articles}

\section{Hospital-related mortality in NSW: preliminary results}

28 Should we screen for colorectal cancer?

\section{Infectious Diseases}

\section{Notifications}

\section{Correspondence}

Please address all correspondence and potential contributions to:

\section{The Editor,}

NSW Public Health Bulletin,

Public Health Division,

NSW Health Department

Locked Bag No 961 ,

Nortb Sydney NSW 2059

Telephone: (02) 3919218

Facsimile: (02) 3919232 


\section{Hospital-related mortality in NSW}

\section{$\checkmark$ Continued from page 25}

principal referral, major referral, major rural base, district high, district - medium, district - low, and community.

CFRs (expressed as percentages) were calculated as follows: $\mathrm{CFR}=($ No. of inpatient deaths/No, of hospital separations) X 100

\section{RESULTS}

Between 1988-89 and 1992-93, the number of hospital inpatients (including day-only patients, i.e. patients admitted and discharged on the same day) increased by 27 per cent from $1,212,524$ to $1,535,451$. Most ( 74 per cent) of this increase was due to a growth in the number of dayonly cases; there was an 84 per cent increase in day-only admissions over the five-year period, compared with a 9 per cent increase in the number of longer-stay patients. In view of the disproportionate growth in day-only patients, who are generally at low risk of dying in hospital, we excluded dayonly cases from our analyses to improve the validity of comparisons across the period.

Excluding day-only patients, there were 1,010,324 separations from, and 23,201 deaths in, NSW hospitals in 1992-93, giving an overall in-hospital mortality rate of 2.3 per cent. This figure has remained relatively stable since 1988-89 (Table 1).

The risk of in-hospital death varied according to principal diagnosis as illustrated in Table 2. The CFR for patients presenting with an aortic aneurysm ranged between 20 and

\section{FIGURE 1}

CRUDE CFR FOR NSW PUBLC HOSPITALS, $92 / 93$ MEDIAN 25-75 PERCENTILE RANGES

Hospital Role

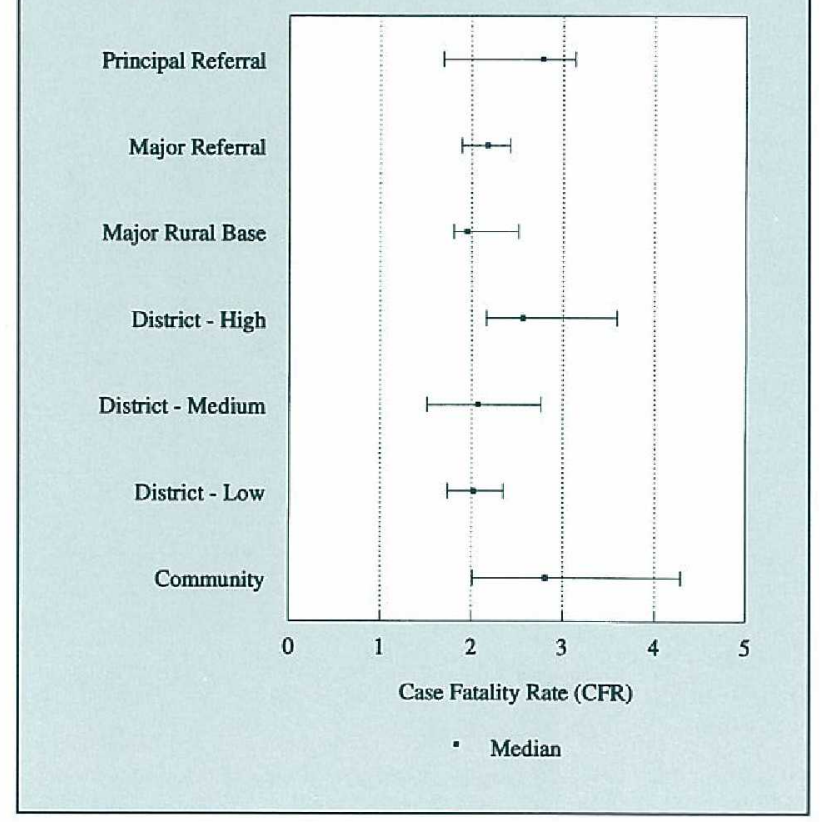

\section{TABLE 1}

UNADJUSTED ALL CAUSES IN-HOSPITAL MORTALITY, NSW 1988-89 TO 1992-93

\begin{tabular}{|rrrr|}
\hline & Deaths & $\begin{array}{r}\text { Total } \\
\text { separations }\end{array}$ & CFR (\%) \\
\hline $1988-89$ & 21,318 & 926,769 & 2.30 \\
$1989-90$ & 22,434 & 969,492 & 2.31 \\
$1990-91$ & 22,014 & 984,269 & 2.23 \\
$1991-92$ & 23,365 & 987,423 & 2.37 \\
$1992-93$ & 23,201 & $1,010,324$ & 2.29 \\
\hline
\end{tabular}

Day-only cases excluded

22 per cent over the five years and for patients with AMI or CVA between 13 and 16 per cent. Among patients with proximal femoral fracture the rate remained around 4 per cent, while nearly 3 per cent of patients with head injury and around 2 per cent of patients having CABG surgery died as inpatients.

The average CFR within acute hospital role groups ranged from 2 to 3 per cent over the five-year period (Table 3 ). In contrast, much higher rates were reported for other hospital groups such as public nursing homes (17 per cent) and public subacute hospitals ( 19 per cent) which included hospices and rehabilitation centres.

Figure 1 depicts the variability of CFRs among public hospitals in 1992-93, displaying the median and interquartile range for each type of hospital. In the same year, the CFR in principal referral hospitals ranged from 1.0 per cent to 3.5 per cent, while for major rural base hospitals the range was between 1.8 per cent and 2.8 per cent, and for public hospitals it was from 0.4 per cent to 11.5 per cent.

\section{DISCUSSION}

Some 44,000 people die in NSW each year and just over half these deaths occur in hospital. In 1992-93 this translated into an all causes in-hospital mortality rate for NSW of 2.3 per cent. How does this compare with other States or countries? While it is of limited value to compare in-hospital mortality rates without adjusting for risk (i.e. using crude rates only), such a comparison does provide a context in which to place the NSW experience. For this purpose we selected the USA as an initial benchmark. In $1987^{4}$ a survey of short-term, general, non-federal hospitals reported an all category mortality rate of 2.9 per cent, and the following CFRs for specific conditions: aortic aneurysm 20.6 per cent, CVA 10.5 per cent, AMI 14.9 per cent, hip fracture 4.2 per cent, and CABG 5.1 per cent. With the notable exception of CABG these figures are generally consistent with the aggregate results from all NSW hospitals. It cannot be concluded from these crude comparisons that outcomes for CABG are better in NSW than in the USA because the rates have not been adjusted for differences in patient characteristics and the impact these might have on outcomes. This draws attention to the importance of appropriate risk-adjustment to allow valid comparisons to be made. 
TABLE 2

UNADJUSTED IN-HOSPITAL MORTALITY FOR

SELECTED PATIENT GROUPS, 1988-89 TO 1992-93

\begin{tabular}{|c|c|c|c|c|c|c|c|}
\hline & Deaths & $\begin{array}{r}\text { Total } \\
\text { separations }\end{array}$ & CFR (\%) & & Deaths & $\begin{array}{r}\text { Total } \\
\text { separations }\end{array}$ & CFR (\%) \\
\hline $\begin{array}{l}\text { CVA } \\
1988-89 \\
1989-90 \\
1990-91 \\
1991-92 \\
1992-93\end{array}$ & $\begin{array}{l}2,036 \\
2,058 \\
2,013 \\
2,136 \\
2,005\end{array}$ & $\begin{array}{l}14,110 \\
14,592 \\
14,866 \\
15,343 \\
15,520\end{array}$ & $\begin{array}{l}14.4 \\
14.1 \\
13.5 \\
13.9 \\
12.9\end{array}$ & $\begin{array}{l}\text { AMI } \\
1988-89 \\
1989-90 \\
1990-91 \\
1991-92 \\
1992-93\end{array}$ & $\begin{array}{l}1,650 \\
1,632 \\
1,630 \\
1,605 \\
1,587\end{array}$ & $\begin{array}{l}10,534 \\
10,829 \\
11,008 \\
11,235 \\
11,192\end{array}$ & $\begin{array}{l}15.7 \\
15.1 \\
14.8 \\
14.3 \\
14.2\end{array}$ \\
\hline $\begin{array}{l}\text { Aortic aneurysm } \\
1988-89 \\
1989-90 \\
1990-91 \\
1991-92 \\
1992-93\end{array}$ & $\begin{array}{l}254 \\
271 \\
295 \\
306 \\
342\end{array}$ & $\begin{array}{l}1,225 \\
1,349 \\
1,417 \\
1,431 \\
1,556\end{array}$ & $\begin{array}{l}20.7 \\
20.1 \\
20.8 \\
21.4 \\
22.0\end{array}$ & $\begin{array}{l}\text { Head injury } \\
1988-89 \\
1989-90 \\
1990-91 \\
1991-92 \\
1992-93\end{array}$ & $\begin{array}{l}214 \\
213 \\
212 \\
211 \\
182\end{array}$ & $\begin{array}{l}7,355 \\
7,469 \\
6,931 \\
6,710 \\
6,593\end{array}$ & $\begin{array}{l}2.92 \\
2.85 \\
3.06 \\
3.14 \\
2.76\end{array}$ \\
\hline $\begin{array}{l}\text { Hip fracture } \\
1988-89 \\
1989-90 \\
1990-91 \\
1991-92 \\
1992-93\end{array}$ & $\begin{array}{l}232 \\
219 \\
218 \\
194 \\
223\end{array}$ & $\begin{array}{l}5,259 \\
5,150 \\
5,197 \\
5,378 \\
5,516\end{array}$ & $\begin{array}{l}4.42 \\
4.25 \\
4.20 \\
3.62 \\
4.04\end{array}$ & $\begin{array}{l}\text { CABG } \\
1988-89 \\
1989-90 \\
1990-91 \\
1991-92 \\
1992-93\end{array}$ & $\begin{array}{r}82 \\
81 \\
122 \\
107 \\
108\end{array}$ & $\begin{array}{l}3,809 \\
4,474 \\
4,836 \\
5,178 \\
5,602\end{array}$ & $\begin{array}{l}2.15 \\
1.81 \\
2.52 \\
2.07 \\
1.93\end{array}$ \\
\hline
\end{tabular}

Day-only cases excluded

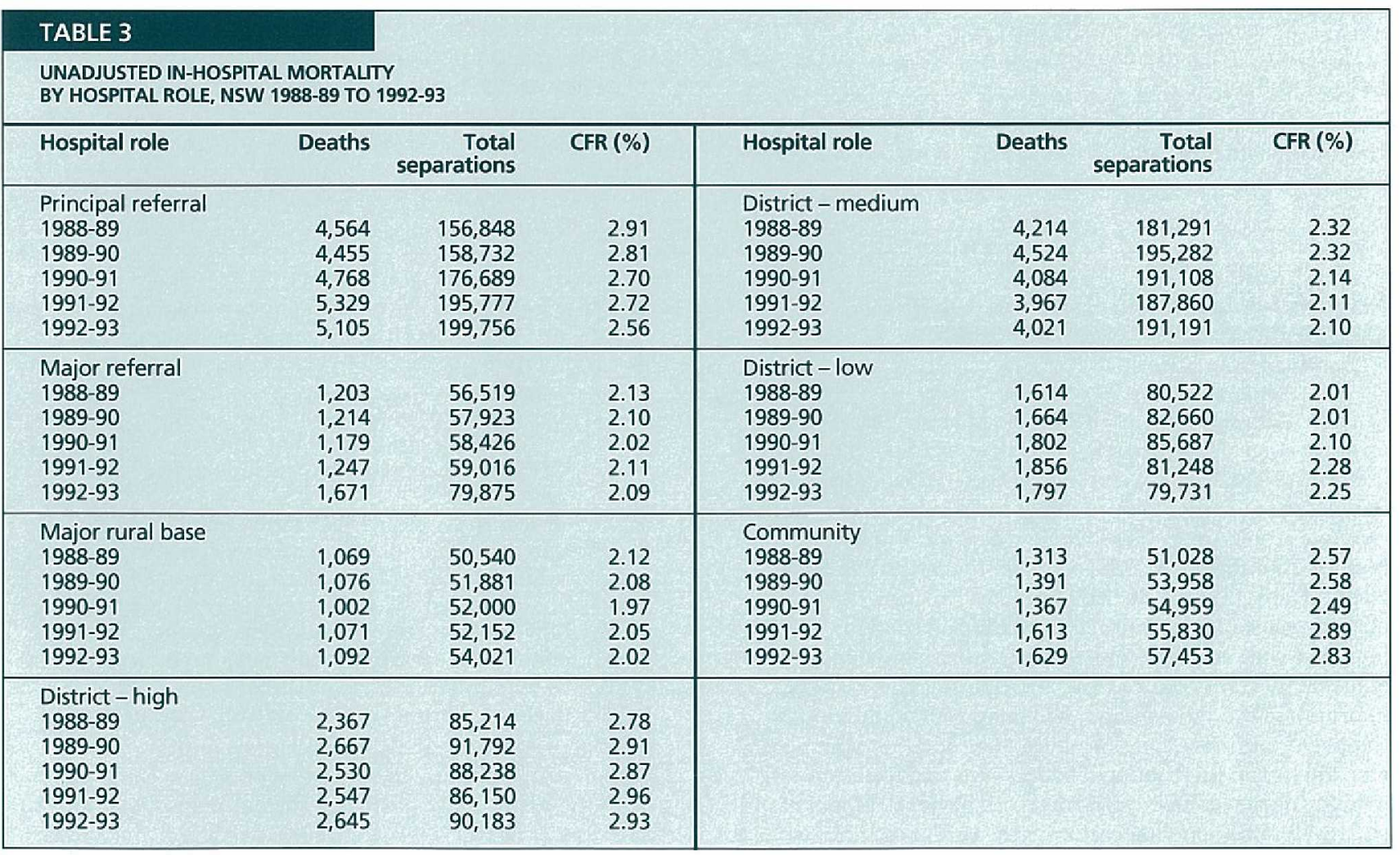

Day-only cases excluded

\section{PUBLIC HEALTH EDITORIAL STAFF}

The Bulletin's editorial advisory panel is as follows:

Dr Sue Morey, Chief Health Officer, Public Health Division, NSW Health Department; Professor Stephen Leeder, Director, Department of Community Medicine, Westmead Hospital; Professor Geoffrey Berry, Head, Department of Public Health, University of Sydney; Dr Christine Bennett, General Manager, Royal Hospital for Women; Dr Michael Frommer, Deputy Director, Epidemiology and Health Services Evaluation Branch, NSW Health Department; Ms Jane Hall, Director, Centre for Health Economics Research and Evaluation; and Ms Lyn Stoker, Acting Manager, Health Promotion Unit.

The editor is Dr George Rubin, Director, Epidemiology and Health Services Evaluation Branch, NSW Health Department.

The Bulletin aims to provide its readers with population health data and information to motivate effective public health action. Articles, news and cornments should be 1,000

words or less in length and include a summary of the key points to be made in the first paragraph. Please submit items in hard copy and on diskette, preferably using WordPerfect 5.1 , to the editor, Public Health Bulletin, Locked Mail Bag 961, North Sydney 2059. Facsimile (02) 3919232.

Please contact your local Public Health Unit to obtain copies of the NSW Public Health Bulletin. 


\section{SHOULD WE SCREEN FOR COLORECTAL CANCER?}

Bernie Towler, Public Health Officer, Epidemiology and Health Services Evaluation Branch;

Les Irwig, A/Professor (Epidemiology), Department of Public Health, University of Sydney;

Marion Haas, Public Health Officer, Epidemiology and Health Services Evaluation Branch;

Angela Plunkett, Associate Lecturer, Department of Public Health, University of Sydney;

Glenn Salkeld, Lecturer (Health Economics), Department of Public Health, University of Sydney.

\section{INTRODUCTION}

n NSW in 1991 colorectal cancer was the second most common cancer affecting women and men, after breast and prostate cancer, respectively'. Because of the burden of this disease and because prevention is not possible, populationbased screening to detect and remove colorectal adenomas and early asymptomatic cancers has been advocated by some ${ }^{2}$. However, the decision to implement population-based screening is a complex one. Early detection and treatment of colorectal neoplasms (adenomas and cancers) must be shown to be effective in reducing disease mortality and any benefits of screening must outweigh potential morbidity caused. Other considerations include the feasibility, cost and acceptability of screening to Australians and the likelihood of patient and physician compliance with a screening program.

We examined the evidence about the effectiveness of screening and related issues to inform screening policy. This included a comprehensive and critical review of the literature, preliminary economic analysis of screening in the Australian health care setting and correspondence with Australian investigators for information about local research relevant to screening. A summary of this review and its recommendations are presented below and in Table 4. The full report, including the tabulated results of the critical appraisal of the literature, is available from the Epidemiology and Health Services Evaluation Branch.

\section{IS SCREENING EFFECTIVE?}

Whether screening is effective is the first and crucial question to ask before embarking on a screening program. Randomised controlled trials provide the best quality evidence about screening effectiveness. There are five large trials (one non-randomised) investigating the effectiveness of screening using the faecal occult blood test (FOBT) Hemoccult ${ }^{34,5,5,7,7,9,10,11,12,13}$. The New York trial ${ }^{12,13}$ is evaluating Hemoccult additional to sigmoidoscopy which was offered to all study participants. The major characteristics and mortality findings of the trials are given in Table 5 . In all trials, Hemoccult positive subjects were referred for further investigation which was mainly colonoscopy, or alternatively, sigmoidoscopy with double contrast barium enema. Colorectal neoplasms detected were removed.

Three of the trials have reported mortality findings, analysed by intention to treat ${ }^{4,11,13}$. Only the Minnesota trial ${ }^{4}$ has reported a statistically significant 33 per cent reduction in colorectal cancer mortality with annual screening (Table 5). However, the findings of the Minnesota trial must be viewed with caution for several reasons. There are inconsistencies in the numbers of colorectal cancers

\section{Hospital-related mortality in NSW}

\section{$\checkmark$ Continued from page 26}

While our development of risk-adjusted indicators is still at an early stage, there are a few excellent examples of clinical groups in NSW that have produced and implemented such indicators to monitor the quality of their services. One such example is the Australian and New Zealand Intensive Care Society (ANZICS). ANZICS, partially funded by the NSW Health Department's Health Outcomes Program, is installing a standard clinical information system in intensive care units throughout Australia to provide riskadjusted mortality data to the participating units. The information from this system will allow individual units to compare their overall performance and condition-specific mortality to an international benchmark and facilitate monitoring of trends in performance. The development of such systems is complementary to the work being carried out in the Epidemiology and Health Services Evaluation Branch.

The next steps in our exploration of hospital mortality will be to:

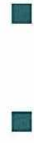

recalculate in-hospital mortality rates adjusting for age, sex and casemix, and condition-specific mortality rates adjusting for age and sex; evaluate methods for using existing inpatient data in the measurement of co-morbidity and severity of illness and in risk adjustment; compare the use of routinely reported inpatient data and these algorithms against results derived from more comprehensive clinical databases, e.g. Trauma Registries;

demonstrate the feasibility and usefulness of linking routinely reported inpatient data to mortality data to extend this analysis to include post-discharge deaths; and

assess the usefulness of additional data items from existing hospital information systems and processes which may be of value in the measurement of comorbidity, severity of illness and risk adjustment. This evaluation will determine whether suitable data items are captured by hospital records, the extent and consistency of recording across institutions and the feasibility of computerisation.

This work will be assisted by a grant from the Commonwealth Government and will include collaboration with the Victorian Department of Health and Community Services.

1. US Congress, Office of Technology Assessment. The Quality of Medical Care: Information for Consumers, OTA-H-386 (Washington, DC. US Government Printing Office, June 1988) Chapter 4 p71. 2. International Classification of Diseases and Causes of Death, 9 th Revision, Clincial Modification Vol 1, 1986. Ann Arbor Michigan Library of Congress No. 77-94472.

3. NSW Public Hospital Comparison Data 1991/2. NSW Health Department, State Health Publication No. (IC) 93-134.

4. Elixhauser A, Andrews RM, and Fox S. Clinical Classification for Health Policy Research: Discharge Statistics by Principal Diagnosis and Procedure. Division of Provider Studies Research Note 17 Agency for Health Care Policy and Research, 1993 Rockville, MD Public Health Service (ACHCPR Publication No. 93-0043) 